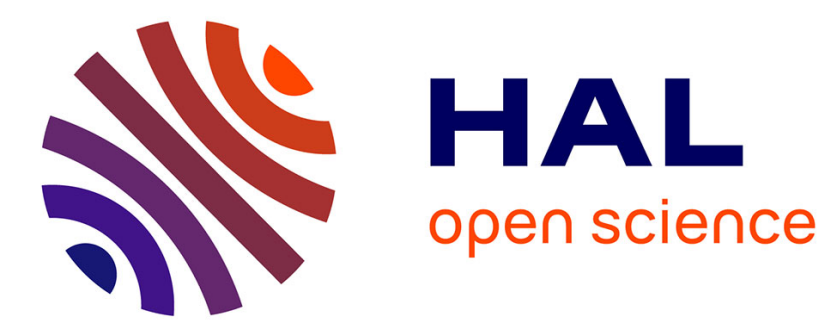

\title{
Space-dependent shift of spectral lines in laser-produced plasmas
}

\author{
P. Jaeglé, A. Carillon, G. Jamelot, C. Wehenkel
}

\section{To cite this version:}

P. Jaeglé, A. Carillon, G. Jamelot, C. Wehenkel. Space-dependent shift of spectral lines in laser-produced plasmas. Journal de Physique Lettres, 1979, 40 (21), pp.551-554. 10.1051/jphyslet:019790040021055100 . jpa-00231686

\section{HAL Id: jpa-00231686 https://hal.science/jpa-00231686}

Submitted on 1 Jan 1979

HAL is a multi-disciplinary open access archive for the deposit and dissemination of scientific research documents, whether they are published or not. The documents may come from teaching and research institutions in France or abroad, or from public or private research centers.
L'archive ouverte pluridisciplinaire HAL, est destinée au dépôt et à la diffusion de documents scientifiques de niveau recherche, publiés ou non, émanant des établissements d'enseignement et de recherche français ou étrangers, des laboratoires publics ou privés. 


\title{
LE JOURNAL DE PHYSIQUE-LETTRES
}

\section{Space-dependent shift of spectral lines in laser-produced plasmas}

\author{
P. Jaeglé, A. Carillon, G. Jamelot and C. Wehenkel \\ GRECO du CNRS «Interaction Laser-Matière », Ecole Polytechnique, 91120 Palaiseau, France \\ and
}

Laboratoire de Spectroscopie Atomique et Ionique, Université Paris-Sud, Bât. 350, 91405 Orsay, France

(Reçu le 26 juin 1979, accepté le 21 septembre 1979)

\begin{abstract}
Résumé. - Un déplacement vers le rouge, variant avec la position du point émetteur sur une distance de plus de 100, est observé pour des raies en ultraviolet extrême provenant d'un plasma produit par laser, le spectre étant obtenu en un seul tir sur cible d'aluminium. Pour le rayonnement venant de la zone de plus forte densité du plasma, ce déplacement parvient à être plus important que l'élargissement des raies. En première approximation, il ne dépend pas de l'épaisseur optique du plasma. Pour rendre compte de ces résultats, plusieurs causes d'effet Stark sont envisagées.
\end{abstract}

Abstract. - A space-dependent red-shift of extreme ultraviolet lines of aluminium laser-plasma is observed on a distance covering more than 100 , in a single-shot experiment. For radiation coming from highest density plasma, the shift can exceed the broadening of the lines. In the first approximation, this shift does not depend on plasma optical thickness. Various aspects of Stark effect are discussed in order to account for these observations.

On account of the role of ion spectra for studying the properties of dense plasmas produced from laserirradiated target, the understanding of the relation between spectral emission and plasma parameters has to be improved. The fact that density and temperature exhibit strong variations along the normal to target surface, and possibly along directions parallel to the surface, is of great importance for physical processes such as generation of magnetic fields [1, 2], emission of fast particles [3], and also because it modifies appreciably the observed features of core emission in the X-ray and extreme ultraviolet (EUV) ranges $[4,5]$. Therefore a large spatial resolution is to be desired in the spectral studies. Here we report the observation of a space-resolved red-shift of spectral lines, measured for a single laser-shot on a distance covering more than $100 \mu$ along the focusing axis of the laser-beam. Such an observation of large systematic shift of ion lines is a new fact in dense plasma diagnostics which, until now, have been centered rather on line broadening $[6,7,8]$.

The experimental arrangement which provides spatial resolution, with a luminosity large enough for recording the EUV spectrum from a single lasershot, uses a toroidal mirror working in an unusual way. Let $R$ and $r$ be the torus radii and $u$ the glancing angle of the radiation on the mirror. Instead of satisfying the stigmatic condition :

$$
r / R=\sin ^{2} u
$$

under which a point of the plasma can be projected as an approximate point on the entrance slit of the spectrograph, we have chosen the radii such that :

$$
r / R=2 \sin ^{2} u \text {. }
$$

Then the distribution of radiation along the entrance slit is fairly well duplicated on the spectrograph detector because all rays coming from a point of the focusing circle of the mirror become parallel to the plane of this circle after being reflected (the horizontal focal line is at infinity). Now, a computer calculation shows that the illumination of the entrance slit plane, from a plasma point near the focusing circle, consists of a curved spot as plotted on figure 1 for $R=200 \mathrm{~cm}$, $r=2 \mathrm{~cm}$ and $u=4^{\circ}$. Thus a point source yields two symmetric lighted spots on the slit itself, at the crossing of the slit with the curve.

When the source point moves along a radius of the focusing circle, that is to say along the laser axis in our experiment, the curved spot on figure 1, runs 


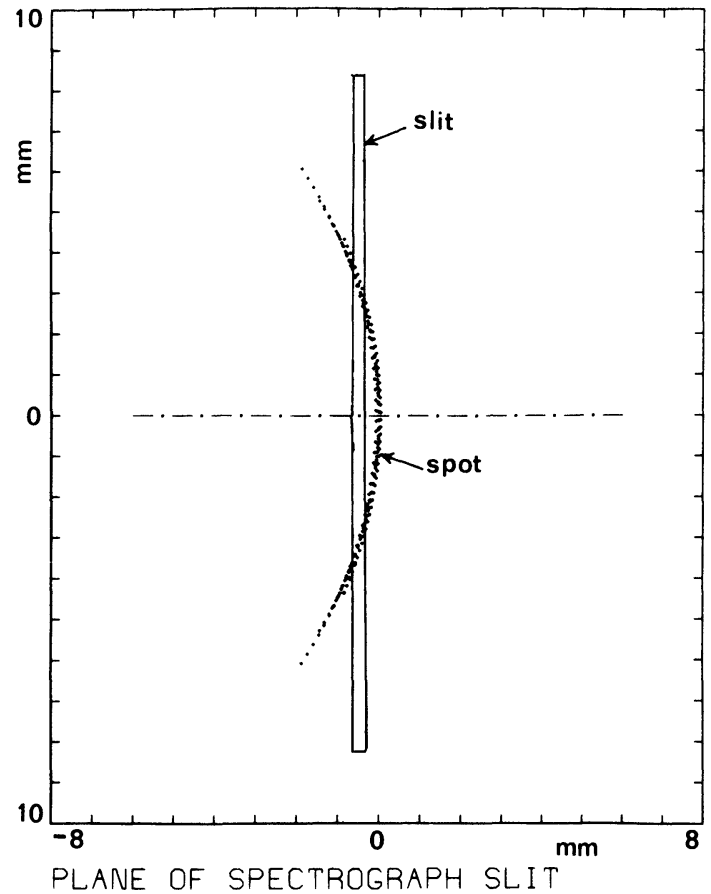

Fig. 1. - Calculated illumination at the spectrograph entrance for a point source in the plasma; a toroidal mirror projecting the horizontal focal line to infinity is used.

horizontally in the plane. A set of such not-separated spots can be seen on the left side of figure 2. The two crossing points of a spot with the slit slide symmetrically along the slit when the spot is shifted in the plane. As their separation varies as the square of the shifting of the source, this system amplifies, on the detector, the distance between the emitting points in the plasma. If an emitted line is submitted to a space-dependent spectral displacement, the dispersion by the spectrograph turns the spatial resolution into a distortion of the line shape, as this is shown on the

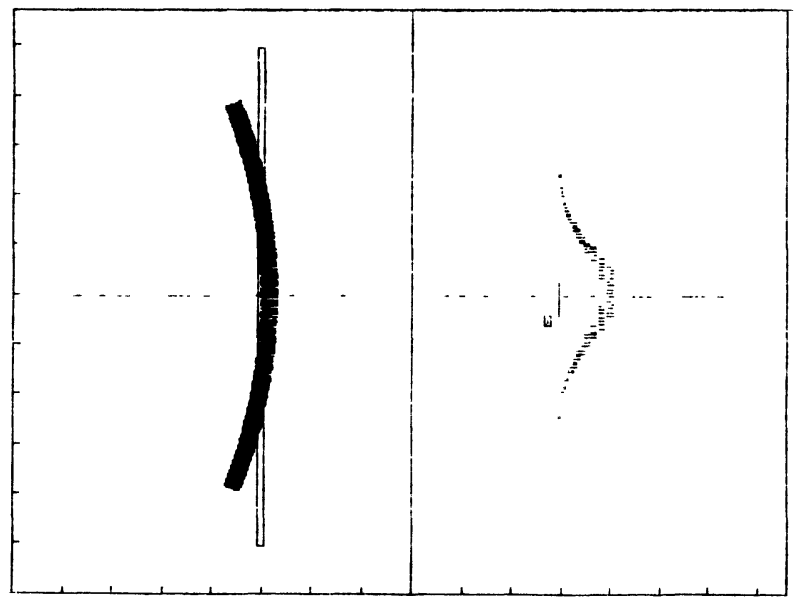

Fig. 2. - Computer simulation of the light spot on the entrance slit (on the left side) and of the line shape due to a space-dependent spectral shift, decreasing exponentially from the target surface (on the right side). This calculated result is to be compared to the experimental shapes exhibited by the spectrum on figure 4 . A striking similarity can be seen. right side of the figure 2 which is discussed below. The calculated limit of the spatial resolution is as large as $5 \mu$. A computer simulation, performed for a $5 \mu$ wide slit, leads to the curve on figure 3 which gives the correspondence between emitting points along the laser axis in the plasma and printed positions on the photographic plate.

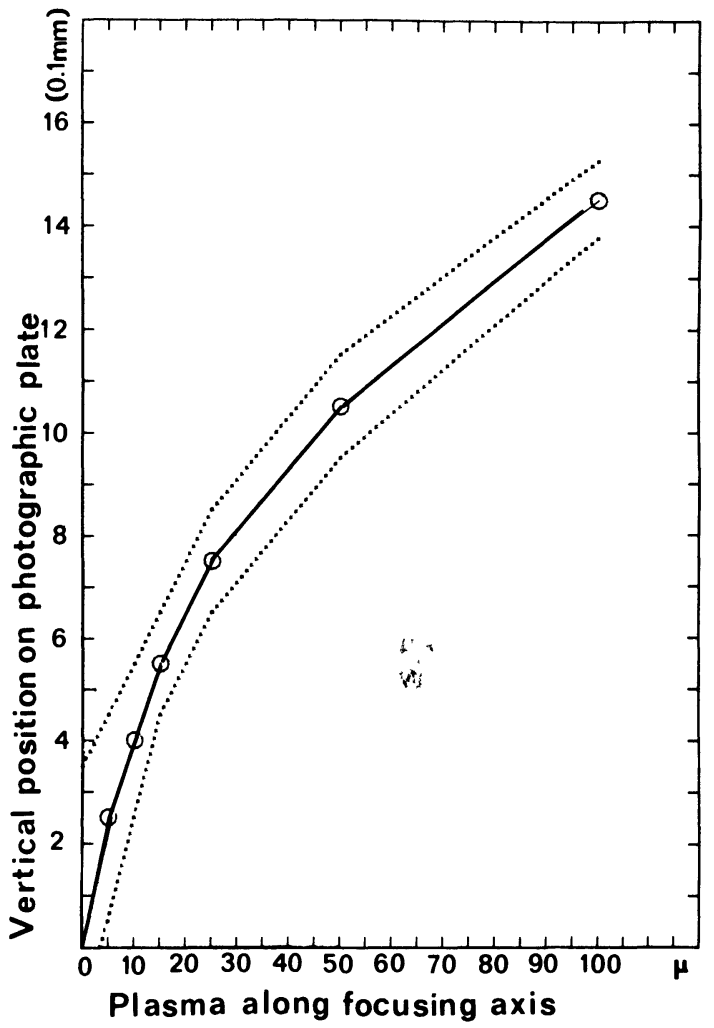

Fig. 3. - Location of plasma emitting points versus printed positions on photographic plate.

Using this system, the spectrum presented on figure 4 has been recorded from a single laser-shot of a Ndlaser focused on an aluminium target. The pulse wid th was $2.5 \mathrm{~ns}$ and the power density $5 \times 10^{14} \mathrm{~W} / \mathrm{cm}^{2}$. From the line intensities of highly charged aluminium ions, a temperature of about $400 \mathrm{eV}$ is assumed for the plasma. The EUV spectrograph used a $2400 \mathrm{~g} / \mathrm{mm}$ grating with a curvature radius of $1 \mathrm{~m}$. Most of lines appearing in the spectrum are due to transitions between levels of quantum number 2 and 3 of ions $\mathrm{Al}^{10+}, \mathrm{Al}^{9+}$ and $\mathrm{Al}^{8+}$. As shown by the picture on figure 4 , these lines exhibit a bend.

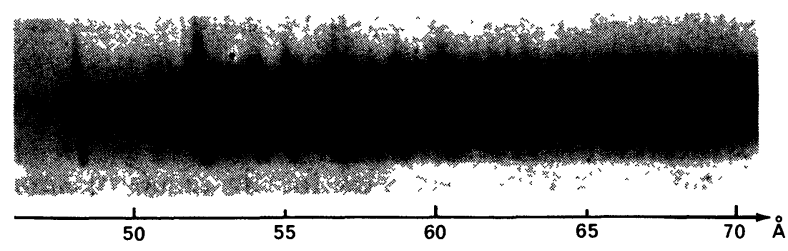

Fig. 4. - Single laser-shot spectrum of aluminium showing the shift of the lines. Unshifted wavelengths are at the ends of the lines, corresponding to emitting points at large distance $(\geqslant 100 \mu)$ from the target; the largest shifts are at the center, corresponding to emission from points near the target $(\simeq 25 \mu)$. 
Keeping in mind the optical design of the experiment, the curvature of spectral lines reveals a spacedependent red-shift of the lines. Assuming such a spectral shift, it is possible to reproduce very well the general feature of the line shape through computer simulation as that can be seen on the right side of figure 2. Experimentally, the fact that the upper and lower ends of the lines are unshifted while the line center moves to the large wavelengths is shown by recording several spectra, at various positions of the target corresponding to different values of plasma parameters, on the same photographic plate. For calculating the line shape represented on figure 2, it has been assumed that an exponentially decreasing spectral red-shift occurs in the plasma from the highest density zone, near the target, to the outside. The gradient length is $100 \mu$. The unperturbed position of the line is pointed out on the figure. The densitometer traces on figure 5 show the experimental shift according to the distance between the target surface and the emitting plasma point, for lines of ions $\mathrm{Al}^{10+}$ $(52.446 \AA$ and $52.299 \AA)$ and $\mathrm{Al}^{9+}(55.376 \AA$ and $55.272 \AA$ ). The maximum shift is of about $0.75 \AA$. This value, which varies little from one line to another in the spectral range displayed on figure 4 , exceeds the width of many lines.

The reabsorption in an optically thick plasma is known to yield broadening of spectral lines. This effect has been extensively calculated in our previous works $[4,9]$, especially in cases where the Doppler shift due to ion expansion velocity yields line asymmetry. Asymmetry results from the opacity of external expanding plasma shell and it appears as a blue-shift of self-reversed profile which allows the top of the line to be practically unshifted. Such features depend strongly on line intensity what is not the case of the shifts observed here. Thus, in the present work, only the line widths are possibly affected by plasma opacity. As to the line shift, Stark effect must be considered for explaining it.

Recent works suggest that an electric field other than the ion microfield can be generated in plasma as a consequence of suprathermal electron production $[10,11,12]$; it is a possible cause of Stark displacement. However, in our time-integrated experiment, it may contribute only a small part in producing the line redshift because its peak value does not exceed $10 \%$ of the ion microfield. Only in a time-resolved experiment, the measurement of the shift could give valuable information on this field which is to be considered in studying transport of energy in the plasma.

The intense field of the Nd-laser can also be invoked as a source of Stark effect. If it would be the case in the experiment reported here, the shift must be sensitive, for instance, to small variations of the focusing distance used for producing the plasma. In fact, the observed shifts are practically constant when this distance varies of more than $\pm 100 \mu$, what must modify significantly the laser intensity in the consi-

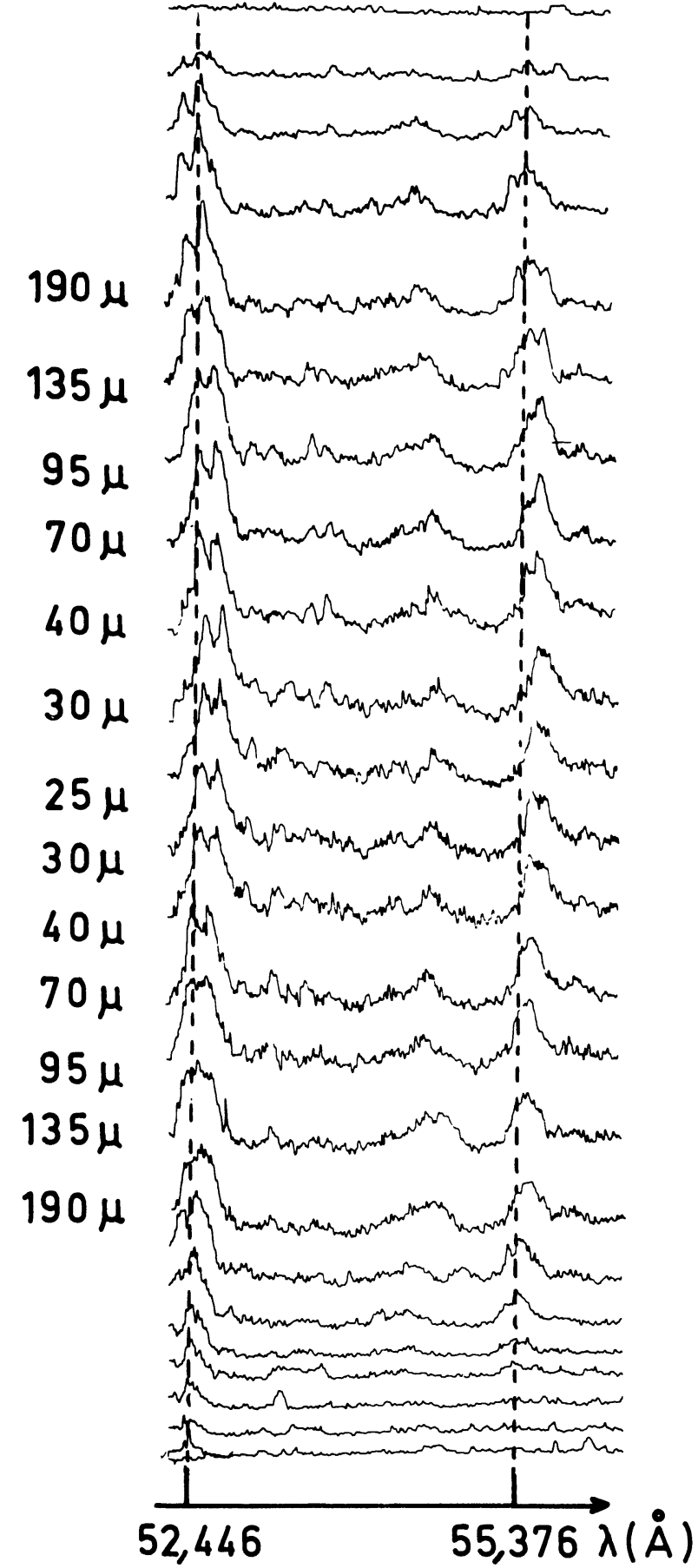

Fig. 5. - Densitometer traces showing the space-dependent redshift of the lines. The distance of the plasma emitting points to the target surface are plotted on the left (in microns) for every spectrum.

dered zone of the plasma. Furthermore, the laser field effect decreases rapidly with the main quantum number of the transition upper-level and thus it is not expected to have a large part in the perturbation regarding the present lines.

The perturbation of ion levels by the next electrically charged particles has thus the main part in the observed features. A red-shift of lines is generally expected from the quadratic quasistatic Stark effect [13] while the impact approximation predicts red or blue shifts 
$[14,15]$. We do not know any attempt for calculating the full profiles of non-hydrogenic lines for plasma density as large as $10^{21}$ particles per cubic centimeter in folding electron and ion contribution, not only in broadening but also in shifting the lines. However, it is possible to ensure that our experimental result is consistent with the experienced values of plasma density in using the following rough approximation. First, on account of the ratio between the electronic temperature and the energy of the transitions under consideration, electron-ion collisions have mostly inelastic effect which will result in broadening rather than in shifting the lines [16]. Neglecting this contribution to the line shift leads to a fairly small overestimation of the ion density. As far as we want merely verify that this density does not exceed the solid target density, this is of no consequence. Second, the order of magnitude of ion density required for producing the observed shift can be deduced from the mean value of the Holtsmark field strength $F$ and from an appropriate expression for the quadratic Stark effect [17] :

$$
\delta E=-n^{6}\left(a_{0}^{3} / Z^{4}\right) F^{2}
$$

leading to :

$$
N=2.54 \times 10^{22} \frac{Z^{3 / 2}}{n^{9 / 2}} \delta E^{3 / 4}
$$

where $N$ is the perturber density in $\mathrm{cm}^{-3}, \delta E$ the shift in $\mathrm{eV}, Z$ the perturber charge and $n$ the quantum number of the upper level. For $Z=10, n=3$ and $\delta E=0.75 \mathrm{eV}$, the maximum value of shift, the density must be :

$$
N=5 \times 10^{21} \mathrm{~cm}^{-3}
$$

for ions, so that the electronic density should be $5 \times 10^{22} \mathrm{~cm}^{-3}$. These values are quite credible at short distance from the target. However, it must be pointed out that, on account of the charge $Z$ and the electronic density, one cannot exclude a contribution to the displacement from the so-called polarisation shift [18].

In conclusion, since reabsorption does not affect significantly the observed effect, the measurement of the line shift will likely be an efficient tool for laserplasma studies above the critical density, for which the laser light frequency is equal to the plasma frequency, provided that further improvement of Stark shift calculation allows an accurate derivation of density from the experimental results.

\section{References}

[1] Stamper, J. A., Laser Interaction and Related Plasma Phenomena, ed. by H. J. Schwarz and H. Hora (Plenum Press, N. Y.) 1977 , vol. $4 B$, p. 721 .

[2] Ahlstrom, H. G., Holzricher, J. F., Manes, K. R., Storm, E. K., Boyle, M. J., Brooks, K. M., HaAs, R. A., PhilLION, D. W., RUPERT, V. C., ref. [1], vol. 4A, p. 437.

[3] YabLonovitch, E., ref. [1], vol. 4A, p. 367.

[4] JaEg Ĺ, P., Jamelot, G., Carillon, A., SUREaU, A., J. Physique Colloq. 39 (1978) C4-75.

[5] APRuzese, J. P., Davis, J., Witney, K. G., J. Quant. Spectrosc. Radiat. Transfer 17 (1977) 557.

[6] Yaakobi, B., Steel, D., Thorsos, E., Hauer, A., Perry, B., Phys. Rev. Lett. 39 (1977) 1526.

[7] Tighe, R. J., Hooper, F. C., Phys. Rev. A 15 (1977) 1773.

[8] Nguyen Hoe, Grumberg, J., Caby, M., Leboucher, E., Couland, C., GRECO «ILM » Internal Report no 6 (1978).

[9] Jamelot, G., Jaeglé, P., Carillon, A., Wehenkel, C., $J$. Physique Colloq. 40 (1979) C1-91.
[10] Shwarz, D., Viremont, J., Jablon, C., Bull. Am. Phys. Soc. 23 (1978) 809.

[11] Pearlman, J. S., Dahlabaka, G. H., Appl. Phys. Lett. 31 (1977) 414

[12] Benjamin, R. F., McCall, G. H., Ehler, A. W., Phys. Rev. Lett. 42 (1979) 890.

[13] Bethe, H. A., SAlPETER, E. E., Quantum Mecanics of one- and two-electron Systems (Springer Verlag, Berlin and New York) 1957, p. 233

[14] GrIEM, H. R., Spectral Line Broadening by Plasmas (Academic Press, New York and London) 1974.

[15] Konjevic, N., Wiese, W. L., J. Phys. Chem. Ref. Data 5 (1976) 259

[16] Baranger, M., Atomic and Molecular Processes, Ed. by D. R. Bates (Academic Press, New York and London) 1962, p. 511.

[17] GRIEM, H. R., ref. [14], p. 25.

[18] GRIEM, H. R., ref. [14], p. 146. 